\title{
Changes in urethral sphincter size following rehabilitation in older women with stress urinary incontinence
}

Stéphanie J. Madill, Stéphanie Pontbriand-Drolet, An Tang, Chantale Dumoulin

First Online: 25 September 2014

\begin{abstract}
Introduction and hypothesis

The purpose of this study was to evaluate the effects of a pelvic floor muscle (PFM)

rehabilitation program on the striated urethral sphincter in women over 60 years with stress urinary incontinence (SUI). We hypothesized that the PFM rehabilitation program would also exercise the striated urethral sphincter and that this would be demonstrated by hypertrophy of the sphincter on magnetic resonance imaging (MRI).

Methods
\end{abstract}

Women with at least weekly episodes of SUI were recruited. Participants were evaluated before and after a 12-week group PFM rehabilitation intervention with T2-weighted fast-spin-echo MRI sequences recorded in the axial plane at rest to assess urethral sphincter size. Data on SUI symptoms and their bother were also collected. No control group was included.

Results

Seventeen women participated in the study. The striated urethral sphincter increased significantly in thickness $(21 \%, p<0.001)$, cross-sectional area $(20 \%, p=0.003)$, and volume (12 $\%, p=0.003$ ) following the intervention. The reported number of incontinence episodes and their bother also decreased significantly.

\section{Conclusions}

This study appears to demonstrate that PFM training for SUI also trains the striated urethral sphincter and that improvement in incontinence signs and symptoms is associated with sphincter hypertrophy in older women with SUI. These findings support previous ultrasound (US) data showing an increase in urethral cross-sectional area following PFM training and extend the previous findings by more specifically assessing the area of hypertrophy and by demonstrating that older women present the same changes as younger women when assessed using MRI data.

Keywords

Urethral sphincterPelvic floor muscle rehabilitationMagnetic resonance imaging 


\section{Introduction}

The striated urethral sphincter has only recently started to garner attention from those interested in rehabilitation for stress urinary incontinence (SUI) where the focus has typically been on retraining the pelvic floor muscles (PFMs). This interest started in the 1990 s when $B \varnothing$ and Stein reported that the striated urethral sphincter contracts synergistically with the PFMs in both continent women and those with SUI $[1,2]$. More recently, it has been reported that the ability to activate the striated urethral sphincter is unrelated to the ability to produce a PFM contraction [3], and that some women without visible PFMs on magnetic resonance imaging (MRI) were still able to increase voluntarily their urethral closure pressure when asked to do a PFM contraction [4].

Interest grew when DeLancey et al. reported that decreased urethral closure pressure is the factor most strongly associated with SUI $[5,6]$. This is supported by both morphological and electromyographic (EMG) evidence. In imaging studies, the striated urethral sphincter has been found to be smaller in women with SUI compared to continent controls [7, 8]. In EMG studies, the striated urethral sphincters of women with SUI demonstrated smaller EMG amplitudes and shorter motor-unit-potential durations with more phases than do continent controls $[9,10]$, indicating primarily myogenic changes.

It is well accepted that PFM rehabilitation is an effective treatment for SUI [11], and since the striated urethral sphincter plays such an important role in SUI, rehabilitation may be effective because it exercises the sphincter along with the PFMs. This idea is supported by a recent publication by McLean et al. who reported that, on US assessment, a 12-week PFM exercise program produced a significant increase in the cross-sectional area of the urethra at the level of the striated urethral sphincter in middle-aged women [12]. Because of limits in the resolution of US images, they were not able to determine which part of the urethra hypertrophied; this limitation can be overcome with MRI. From this, we hypothesized that PFM rehabilitation for older women with SUI would train the striated urethral sphincter and that this would lead to measurable hypertrophy of the striated urethral sphincter on MRI.

\section{Materials and methods}

This study was a secondary analysis of data recorded for a study that examined the effects of PFM rehabilitation on continence, PFM function, and morphology, employing a quasiexperimental pretest-posttest design [13]. The secondary analysis does not include a control group because the initial study design did not require one. Participants were evaluated before and after a 12-week group PFM rehabilitation intervention.

\section{Participants}

Community-dwelling women $\geq 60$ years were recruited using newspaper advertisements and from participating urology and urogynecology clinics. Participants were included if they experienced at least weekly episodes of UI and presented with $\geq 80 \%$ SUI symptoms per history 
and the Three Incontinence Questions (3IQ) [14]. Women taking hormone replacement therapy were admissible as long as their prescriptions had been stable for at least 6 months. Women were excluded if they were unable to understand either French or English; had chronic constipation (per the Rome III criteria) [15]; pelvic organ prolapse (POP) $\geq 2$ according to the POP Quantification system [16]; were taking medications known to affect continence; had mobility, medical, or psychological problems that would prevent them from completing the assessments or the exercise program $[17,18]$; and/or had a condition or implant that contraindicated MRI scanning. The secondary analysis received ethical approval from the institutional ethics committee and from the ethics committees at each of the participating hospitals. Each volunteer provided written informed consent prior to the initial assessment.

\section{Intervention protocol}

The study involved a 12-week PFM rehabilitation program with assessments at baseline and immediately following the intervention. At the initial assessment demographic, medical history and general quality of life (QoL) assessed on the Short-Form Health Survey of 12 Questions (SF12) were collected. The participants were also individually instructed to perform PFM contractions correctly by an experienced pelvic floor physiotherapist. The intervention involved weekly, 1-h PFM group exercise classes lead by another experienced pelvic floor physiotherapist. Participants were required to complete at least ten classes to have been considered as having completed the intervention. Each group consisted of a maximum of eight participants. Each class followed a strict protocol to ensure that the sessions were comparable, both among groups and between teachers. The exercise classes included maximum voluntary PFM contractions (MVCs), maximum PFM contractions with superimposed rapid contractions (flicks), controlled PFM contractions to $50 \%, 100 \%, 50 \%$ and then relaxed (podium exercises), and PFM precontraction prior to coughing (the Knack) [19], performed in supine, four-point kneeling, sitting, and standing positions. Participants were verbally encouraged throughout to perform the exercises to the maximum of each one's ability. Exercises progressed in number, intensity, and hold time every 4 weeks to provide a progressive challenge. Education, breathing, gentle stretching, core strengthening, and balance exercises were also included in the exercise classes.

The participants also performed home PFM exercises for 15 min 5 days a week. They recorded these exercises in a diary, which was used during the classes to monitor adherence. As the diaries were not collected, they were not analyzed. The PFM exercise program included exercises to train motor control, strength, power, endurance, and functional activities. Exercise number, intensity, and body position were advanced every 4 weeks: from six repetitions with a 6-s hold performed supine, to eight repetitions with an 8-s hold performed sitting, to ten repetitions with a 10 -s hold performed standing. 


\section{Outcome measures}

Continence function

Incontinence symptoms were evaluated with a 3-day bladder diary, the Urogenital Distress Inventory (UDI), and the Incontinence Impact Questionnaire (IIQ) [20]. The bladder diary included the number of leakage episodes, voids, pads used. The UDI and IIQ were scored as described by Shumaker et al. [21], and are valid and reliable measures of incontinence-related QoL in women [22].

Urethral size

Urethral size was evaluated with MRI recorded in the axial plane using a Siemens 3.0 T Magnetom Trio with an IPAT torso/pelvis coil centered at the symphysis pubis. The resting images were acquired using T2-weighted fast-spin-echo sequences [20 slices, field of view $24 \times$ $24 \mathrm{~cm}$, matrix $512 \times 256$, thickness $5 \mathrm{~mm}$, gap $1 \mathrm{~mm}$, flip angle $180^{\circ}$, repetition time (TR) 4,190 ms, echo time (TE) 134 ms, bandwidth $130 \mathrm{~Hz}$ /pixel, number of excitations (NEX) 1, scan duration $146 \mathrm{~s}$ ]. The volunteers were instructed to lie still and breathe normally during the scan. Measurements were made by evaluators blinded to the testing session using Image J software (version 1.42, open source, National Institutes of Health, Bethesda, MD, USA) according to the method described by Morgan et al. [8]. The outside diameter of the striated urethral sphincter and the diameter of the urethra alone were measured from left to right to avoid any distortion resulting from inclination of the urethra in the sagittal plane. Measurements were made from each slice that included the striated urethral sphincter, starting with the slice immediately inferior to the bladder neck and moving down (Fig. 1).

A $B$

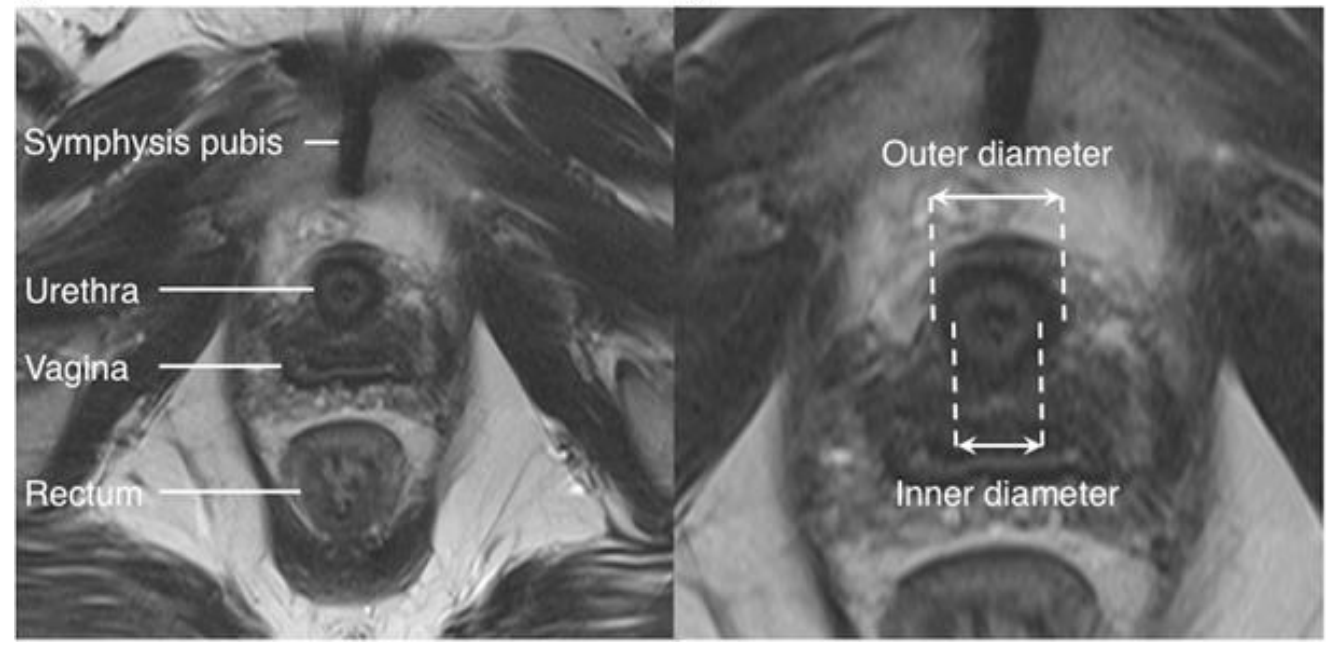

Fig. 1 Axial plane image at the level of the urethral sphincter showing how the outer diameter-including the striated urethral sphincter, smooth muscle, submucosa, and mucosa-and the inner diameter, excluding the striated urethral sphincter, were measured 
Axial plane image at the level of the urethral sphincter showing how the outer diameterincluding the striated urethral sphincter, smooth muscle, submucosa, and mucosa-and the inner diameter, excluding the striated urethral sphincter, were measured

The total striated urethral sphincter thickness was determined by subtracting the inner diameter from the outer diameter to exclude the smooth muscle, submucosa, mucosa, and lumen. The mean thickness of the sphincter in the first two slices in which it was visible was used in all calculations. The length of the sphincter was estimated by multiplying the number of slices in which the sphincter was visible by the sum of the slice thickness $(5 \mathrm{~mm})$ and the interslice gap (1 $\mathrm{mm}$ ). Standard formulas for the area of a circle (area $=\pi \mathrm{R} 2$ ) and the volume of a cylinder (volume $=\pi R 2 \times$ length) were used to calculate the cross-sectional area and the volume of the striated urethral sphincter, respectively. In order to control for changes in the urethra itself, the calculations described above were also made for the urethra alone (inner diameter). All calculations were made with the assessor blinded to the testing session. The test-rest reliability of the measurements was assessed for this data set and found to be very good; the interrater intraclass correlation coefficients (two-way mixed-effects model) ranged between 0.82 and 0.92 , with mean percent errors (estimates of measurement stability) ranging from 12 to $15 \%$.

\section{Sample size and statistical analysis}

Statistical analyses were performed with Minitab v16.2 (State College, PA, USA). Sample size was set a priori for the larger study. As this was a secondary analysis, no power calculation was performed. Given that data were normally distributed, outcome measures (symptoms and morphology) were compared between testing sessions using repeated-measures analyses of variance (ANOVA) with the subject as the random factor and time as the fixed factor. The Bonferroni method was used to control for multiple comparisons.

\section{Results}

Sample

Seventeen women participated in this study: age $68.9 \pm 5.5$ years, $1.4 \pm 1.3$ pregnancies, $1.4 \pm 1.2$ total deliveries, $1.1 \pm 1.3$ vaginal deliveries, and $\mathrm{BMI} 26.31 \pm 4.04 \mathrm{~kg} / \mathrm{m} 2$. Twenty-seven women were recruited; however, eight dropped out due to family, health, or personal reasons and one was excluded because she was unable to complete the initial assessment. None of the participants reported any adverse effects from the exercise program; one withdrew because she reported the program was "too hard." There were no significant differences between women who participated and those who withdrew for any demographic characteristic examined.

\section{Continence function}

Continence function improved for all of participants following the intervention. The mean number of leakage episodes decreased from $4.6 \pm 4.2$ to $1.1 \pm 1.6(p=0.003)$ in 3 days, with ten of the participants ( $59 \%$ ) reporting no leakage episodes at all after treatment. There was no 
change in the number of voids recorded on the diary. The mean number of pads used decreased from $2.1 \pm 2.6$ to $0.4 \pm 1.0(p=0.01)$ in 3 days. Mean UDI scores decreased significantly, from $98.50 / 300 \pm 41.9$ to $51.96 / 300 \pm 28.6(p<0.001)$, indicating that the number of symptoms and their bother improved. The mean IIQ scores also decreased significantly, from 39.72/400 \pm 40.2 to $10.28 / 400 \pm 16.8$ ( $p=0.002$ ), indicating that incontinence was having less of an impact on ability to participate in daily activities. The IIQ includes two QoL impact questions: "How much of a problem is your incontinence?" and "Please rate the effect of your incontinence on your QoL." They were scored separately using $10-\mathrm{cm}$ visual analog scales (VAS), and both improved following treatment: from $4.4 \pm 2.1$ to $2.5 \pm 2.5(p=0.01)$ and from $4.3 \pm 2.3$ to $1.6 \pm 1.9$ $(p<0.001)$, respectively.

Urethral sphincter size

The mean length of the striated urethral sphincter did not change with treatment, and mean thickness (21.4\%), cross-sectional area (20.4\%), and volume (12.1\%) increased significantly following the intervention (Table 1). There was no change in diameter, cross-sectional area, or volume of the urethra alone.

\section{Table 1}

\begin{tabular}{|c|c|c|c|c|c|c|}
\hline \multicolumn{7}{|c|}{$\begin{array}{l}\text { Striated urethral sphincter and overall uret } \\
\text { pelvic floor muscle rehabilitation program }\end{array}$} \\
\hline & \multicolumn{3}{|c|}{$\begin{array}{l}\text { Striated urethral } \\
\text { sphincter }\end{array}$} & \multicolumn{3}{|c|}{ Overall urethral size } \\
\hline & Pre & Post & $\begin{array}{l}P \\
\text { value }\end{array}$ & Pre & Post & $\begin{array}{l}P \\
\text { value }\end{array}$ \\
\hline $\begin{array}{l}\text { Thickness/diameter } \\
(\mathrm{mm})\end{array}$ & $\begin{array}{l}2.8 \\
\pm 1.1\end{array}$ & $\begin{array}{l}3.4 \\
\pm 1.2\end{array}$ & $<0.001$ & $\begin{array}{l}11.7 \\
\pm 1.6\end{array}$ & $\begin{array}{l}11.6 \\
\pm 1.8\end{array}$ & 0.33 \\
\hline $\operatorname{Area}\left(\mathrm{mm}^{2}\right)$ & $\begin{array}{l}58.9 \\
\pm \\
26.3\end{array}$ & $\begin{array}{l}70.9 \\
\pm \\
26.4\end{array}$ & 0.003 & $\begin{array}{l}110.0 \\
\pm \\
27.8\end{array}$ & $\begin{array}{l}107.9 \\
\pm \\
32.0\end{array}$ & 0.47 \\
\hline Length (mm) & $\begin{array}{l}18.0 \\
\pm \\
2.3\end{array}$ & $\begin{array}{l}18.0 \\
\pm 2.3\end{array}$ & 0.98 & $\begin{array}{l}18.0 \\
\pm 2.3\end{array}$ & $\begin{array}{l}18.0 \\
\pm 2.3\end{array}$ & 0.98 \\
\hline Volume (ml) & $\begin{array}{l}1.07 \\
\pm \\
0.6\end{array}$ & $\begin{array}{l}1.2 \pm \\
0.5\end{array}$ & 0.003 & $\begin{array}{l}2.7 \pm \\
0.6\end{array}$ & $\begin{array}{l}2.9 \pm \\
0.7\end{array}$ & 0.97 \\
\hline
\end{tabular}

Overall urethral size is the diameter of the entire urethra, including striated urethral sphincter, smooth muscle, endothelium, and lumen; area and volume were calculated using this diameter. Length is the same for both the striated urethral sphincter and overall urethral size because only slices that included the striated urethral sphincter were included in the calculations of area and volume 
Overall urethral size is the diameter of the entire urethra, including striated urethral sphincter, smooth muscle, endothelium, and lumen; area and volume were calculated using this diameter. Length is the same for both the striated urethral sphincter and overall urethral size because only slices that included the striated urethral sphincter were included in the calculations of area and volume

\section{Discussion}

This study demonstrated that PFM rehabilitation produces hypertrophy of the striated urethral sphincter in older women with SUI concurrently with clinically significant improvements in incontinence symptoms [23-25]. This suggests that one mechanisms by which PFM rehabilitation restores continence is through training the sphincter.

Overall, evaluations were well tolerated, except for one woman who became claustrophobic in the MRI scanner and could not complete the assessment. Prior to enrolment, potential volunteers were asked about claustrophobia during screening, but, as the MRI scan was a novel experience for most participants, the screening was not able to identify everyone who might find the experience anxiety provoking. The one woman who withdrew because she found the program "too hard" had more comorbidities and reported a lower level of daily activity than the other participants, even though she met the inclusion criteria for mobility. This might have been the reason she did not complete the intervention.

These results are consistent with a recent study that found that on US imaging, PFM rehabilitation for SUI increased the urethral cross-sectional area [12] and with previous findings that PFM rehabilitation improves women's ability to increase urethral pressure with a voluntary PFM contraction [26]. This study extends the findings of the recent McLean et al. [12] study in two ways: first, by using MRI, we were able to differentiate between smooth and striated sphincter muscle layers and to determine that the change occurred in the striated urethral sphincter; second, women were older than those in the McLean study. These findings suggest that not only does the striated urethral sphincter contract synergistically with PFMs during both voluntary and automatic contractions [1, 2, 4], PFM rehabilitation stresses the striated urethral sphincter sufficiently to produce a training effect: muscular hypertrophy.

In this study, the initial measures of sphincter thickness and area were similar to the values for sphincter thickness and area reported by Morgan et al. for women with SUI [8]. Following the intervention, sphincter thickness and area measurements were similar to those found in continent women by both Morgan et al. and Preyer et al. [8, 27]. The increases in thickness are also similar in magnitude to those reported by Athanasiou et al. and Duckett et al. in studies of the effects of duloxetine $[28,29]$. These increases in sphincter size appear to be clinically relevant; thickness and cross-sectional area both increased by $\sim 20 \%$, which is well above the estimated mean percent error of 12-15\%. Further, when improvements in continence are considered along with morphological changes, these results suggest that the training effect 
produced appears to be sufficient to overcome deficiencies in urethral pressure in women with SUI found by DeLancey's group $[5,6]$.

The sphincter volume measures calculated in this study were larger initially than were the volumes calculated in Morgan et al.'s study; and following the intervention, the calculated volumes were larger than those of continent women in both Morgan et al.'s and Preyer et al.'s studies $[8,27]$. This may be explained by a longer interval between MRI slices used in our study $(6 \mathrm{~mm})$, compared with Morgan's $(5 \mathrm{~mm})$ and Preyer's $(4.4 \mathrm{~mm})$ studies. Hence, if the sphincter was partially visualized in the top or bottom slice, it would still be included in our measurements, a phenomenon known as "partial volume averaging." Since the primary goals of the larger study, of which this study was a secondary analysis, were to assess the effects of PFM rehabilitation on PFM measures and pelvic organ support, we introduced a 1-mm gap between $5-\mathrm{mm}$ slices to improve image quality and to extend the cephalocaudal coverage. This does not limit the study because the higher soft tissue contrast improved precision of urethral sphincter measurements on axial images and, concurrently, calculations of cross-sectional area. However, we point out the need for caution when comparing estimates of sphincter volume between studies due to slightly different MRI acquisition protocols. The volume increased by $12 \%$, which is on the edge of clinical relevance. The smaller relative increase in volume is likely related to how we calculated sphincter length, as discussed above.

Strengths of the study include the blinding of assessors to the testing session and the very good test-retest reliability of MRI measurements. The primary limitation is that we did not include a control group not receiving the intervention for comparison. Therefore, it is not possible to state that the intervention caused the sphincter to hypertrophy or that the hypertrophy of the striated urethral sphincter caused the improvements in continence; it is also not possible to determine how much the sphincter hypertrophy contributed to improvements relative to other changes, such as improvements in PFM strength or changes in contraction timing. However, previous research demonstrated that in women with SUI who do not receive treatment, symptoms tend stay the same or deteriorate over time; that women lose muscle mass from the striated urethral sphincter as they age; and there is a trend toward a decrease in urethral crosssectional area in controls $[11,12,30]$. It therefore seems unlikely that these changes were the product of time or the natural disease process. Another limitation is that this study only included women $\geq 60$ years, which limits generalizability of the results: the McLean study included younger women (mean age 49.5 years) but found very similar results, suggesting that sphincter hypertrophy with PFM rehabilitation is not restricted to older women. Conversely, the inclusion of only women $>60$ could be seen as a strength of our study, because it is well documented that older women have fewer muscle fibers in both the smooth muscle and the striated urethral sphincters and have lower urethral closure pressures than do younger women [31-33]. These findings suggest that PFM rehabilitation may help reduce the impact of agerelated deterioration of urethral sphincters. The sample size was small; however, significant changes were still detected, indicating a large effect size. 
Future research should seek to replicate these results in a larger sample including a control group and to investigate whether the same improvements in coordination and motor control found in the PFMs following rehabilitation are also seen in the sphincter using both EMG of the striated urethral sphincter and urethral pressure [13]. Studies should also investigate whether sphincter hypertrophy is associated with an increased ability to generate urethral pressure, as is suggested by the improvement in continence found in this study. The reproducibility of a similar rehabilitation program on urethral sphincter training and continence in young women and men should be explored in future studies, as these groups demonstrate different underlying deficits. The reproducibility of these findings should also be investigated in women with severely damaged PFMs to determine whether their ability to increase urethral closure pressure can be harnessed therapeutically to improve continence [44]. The effect of PFM rehabilitation on the striated urethral sphincter in women who demonstrate severe sphincter denervationreinnervation injuries on needle EMG should be investigated as well, as this would shed light on how effectively the body is able to repair these injuries.

\section{Conclusions}

This study appears to demonstrate that PFM training for SUI also trains the striated urethral sphincter in older women and that improvements in continence are associated with striated urethral sphincter hypertrophy. The lack of a control group limits the interpretation of our findings, and future research should seek to replicate them under controlled circumstances. These findings support previous research that demonstrated increased urethral cross-sectional area following PFM exercise using US. These findings are important because they increase the understanding of how PFM exercise works to improve continence and demonstrate that PFM exercise can help overcome age-related atrophy of the striated urethral sphincter.

\section{Acknowledgments}

The authors acknowledge the assistance of the following people and offer each one our sincere thanks: Martine Bernard, Jacques Corcos, Marie-Claude Lemieux, Lisa Merovitz, Cara Tannenbaum, and Jens-Erik Walter assisted with recruitment. Janic Bergeron, Claudia Botelho, Nancy Boudreau, Marjolaine Caya, Sima Chiva-Razavi, André Cyr, Valérie Elliott, Carollyn Hurst, Muriel Jadin, Sophie Lapointe, Alexandre Prud'homme-Delage, and Rébecka Ouellette participated in and assisted with screening, data collection, teaching the rehabilitation classes, and data entry and processing. This study could not have been completed without the financial support of the Canadian Institutes of Health Research, the Canadian Continence Foundation, and les Fonds de recherche en santé du Québec.

\section{Conflict of interest}

None. 


\section{References}

1. BøK, Stien R (1994) Needle EMG registration of striated urethral wall and pelvic floor muscle activity patterns during cough, valsalva, abdominal, hip adductor, and gluteal muscle contractions in nulliparous healthy females. Neurourol Urodyn 13:35-41

2. BøK, Stien R, Kulseng-Hanssen $S$, Kristofferson M (1994) Clinical and urodynamic assessment of nulliparous young women with and without stress incontinence symptoms: a case-control study. Obstet Gynecol 84(6):1028-1032

3. Kenton K, Brubaker L (2002) Relationship between levator ani contraction and motor unit activation in the urethral sphincter. Am J Obstet Gynecol 187(2):403-406

4. Miller JM, Umek WH, Delancey JO, Ashton-Miller JA (2004) Can women without visible pubococcygeal muscle in MR images still increase urethral closure pressures? Am J Obstet Gynecol 191(1):171-175. doi:10.1016/j.ajog.2004.03.082

5. DeLancey JO, Miller JM, Kearney R, Howard D, Reddy P, Umek W, Guire KE, Margulies RU, Ashton-Miller JA (2007) Vaginal birth and de novo stress incontinence: relative contributions of urethral dysfunction and mobility. Obstet Gynecol 110(2 Pt 1):354-362.

doi:10.1097/01.AOG.0000270120.60522.55

6. DeLancey JO, Trowbridge ER, Miller JM, Morgan DM, Guire K, Fenner DE, Weadock WJ, Ashton-Miller JA (2008) Stress urinary incontinence: relative importance of urethral support and urethral closure pressure. 179 (6):2286-2290; discussion 2290. doi:10.1016/j.juro.2008.01.098

7. Athanasiou S, Khullar V, Boos K, Salvatore S, Cardozo L (1999) Imaging the urethral sphincter with three-dimensional ultrasound. Obstet Gynecol 94(2):295-301

8. Morgan DM, Umek W, Guire K, Morgan HK, Garabrant A, DeLancey JO (2009) Urethral sphincter morphology and function with and without stress incontinence. J Urol 182(1):203209. doi:10.1016/j.juro.2009.02.129

9. Kenton K, Mueller E, Brubaker L (2011) Continent women have better urethral neuromuscular function than those with stress incontinence. Int Urogynecol J 22(12):1479-1484.

doi:10.1007/s00192-011-1447-7

10. Takahashi S, Homma Y, Fujishiro T, Hosaka Y, Kitamura T, Kawabe K (2000)

Electromyographic study of the striated urethral sphincter in type 3 stress incontinence: evidence of myogenic-dominant damages. Urology 56(6):946-950

11. Hay-Smith J, Berghmans B, Burgio K, Dumoulin C, Hagen S, Moore K, Nygaard I, N'dow J (2009) Committee 12 adult conservative management. In: Abrams P, Cardozo L, Khoury S, Wein A (eds) Incontinence, 4th edn. Health Publications Ltd., Paris 
12. McLean L, Varette K, Gentilcore-Saulnier E, Harvey MA, Baker K, Sauerbrei E (2013) Pelvic floor muscle training in women with stress urinary incontinence causes hypertrophy of the urethral sphincters and reduces bladder neck mobility during coughing. Neurourol Urodyn 32(8):1096-1102. doi:10.1002/nau.22343

13. Madill SJ, Pontbriand-Drolet S, Tang A, Dumoulin C (2013) Effects of PFM rehabiliation and PFM function and morphology in older women. Neurourol Urodyn. doi:10.1002/nau.22370

14. Brown JS, Bradley CS, Subak LL, Richter HE, Kraus SR, Brubaker L, Lin F, Vittinghoff E, Grady D (2006) The sensitivity and specificity of a simple test to distinguish between urge and stress urinary incontinence. Ann Intern Med 144(10):715-723

15. Longstreth GF, Thompson WG, Chey WD, Houghton LA, Mearin F, Spiller RC (2006) Functional bowel disorders. Gastroenterology 130(5):1480-1491.

doi:10.1053/j.gastro.2005.11.061

16. Haylen BT, de Ridder D, Freeman RM, Swift SE, Berghmans B, Lee J, Monga A, Petri E, Rizk $D E$, Sand PK, Schaer GN (2010) An International Urogynecological Association (IUGA)/International Continence Society (ICS) joint report on the terminology for female pelvic floor dysfunction. 29 (1):4-20. doi:10.1002/nau.20798

17. Koelbl H, Nitti V, Baessler K, Salvatore S, Sultan A, Yamaguchi O (2009) Committee 4: pathophysiology of urinary incontinence, faecal incontinence and pelvic organ prolapse. In: Abrams P, Cardozo L, Khoury S, Wein A (eds) Incontinence, 4th edn. Health Publications Ltd., Paris

18. Abrams P, Cardozo L, Khoury S, Wein A (eds) (2002) Incontinence, 2nd edn. Health Publications Ltd., Paris

19. Miller JM, Ashton-Miller JA, DeLancey JOL (1998) A pelvic muscle precontraction can reduce cough-related urine loss in selected women with mild SUI. J Am Geriatr Soc 46(7):870-874

20. Staskin D, Kelleher C, Avery K, Bosch R, Cotterill N, Coyne K, Emmanuel A, Yoshida M, Kopp Z (2009) Committee 5A: initial assessment of urinary and faecal incontinence in adult male and female patients. In: Abrams P, Cardozo L, Khoury S, Wein A (eds) Incontinence, 4th edn. Health Publications Ltd., Paris

21. Shumaker SA, Wyman JF, Uebersax JS, McClish D, FantI JA (1994) Health-related quality of life measures for women with urinary incontinence: the incontinence impact questionnaire and the urogenital distress inventory. continence program in women (CPW) research group. Qual Life Res 3(5):291-306

22. Hagen S, Hanley J, Capewell A (2002) Test-retest reliability, validity and sensitivity to change of the urogenital distress inventory and the incontinence impact questionnaire. Neurourol Urodyn 21:534-539 
23. Yalcin I, Peng G, Viktrup L, Bump RC (2010) Reductions in stress urinary incontinence episodes: what is clinically important for women? Neurourol Urodyn 29(3):344-347.

doi:10.1002/nau.20744

24. Corcos J, Behlouli H, Beaulieu S (2002) Identifying cut-off scores with neural networks for interpretation of the incontinence impact questionnaire. Neurourol Urodyn 21(3):198-203

25. Barber MD, Spino C, Janz NK, Brubaker L, Nygaard I, Nager CW, Wheeler TL (2009) The minimum important differences for the urinary scales of the pelvic floor distress inventory and pelvic floor impact questionnaire. Am J Obstet Gynecol 200(5):580.

doi:10.1016/j.ajog.2009.02.007, e581-587

26. Teleman PM, Gunnarsson M, Lidfeldt J, Nerbrand C, Samsioe G, Mattiasson A (2003) Urethral pressure changes in response to squeeze: a population-based study in healthy and incontinent 53- to 63-year-old women. Am J Obstet Gynecol 189(4):1100-1105

27. Preyer O, Brugger PC, Laml T, Hanzal E, Prayer D, Umek W (2011) High resolution magnetic resonance imaging of urethral anatomy in continent nulliparous pregnant women. Eur J Radiol 80(3):736-739. doi:10.1016/j.ejrad.2010.08.046

28. Athanasiou S, Chaliha C, Digesu GA, Sotiropoulou M, Georgoulias N, Khullar V, Antsaklis A (2007) The effects of duloxetine on urethral function and sphincter morphology. Int Urogynecol J 18(7):763-767. doi:10.1007/s00192-006-0230-7

29. Duckett J, Patil A, Aggarwal I (2008) The effect of duloxetine on urethral sphincter morphology. Ultrasound Obstet Gynecol 31(2):206-209. doi:10.1002/uog.5202

30. Carlile A, Davies I, Rigby A, Brocklehurst JC (1988) Age changes in the human female urethra: a morphometric study. J Urol 139:532-535

31. Clobes A, DeLancey JO, Morgan DM (2008) Urethral circular smooth muscle in young and old women. Am J Obstet Gynecol 198(5):587. doi:10.1016/j.ajog.2008.03.009, e581-585

32. Perucchini D, DeLancey JO, Ashton-Miller JA, Peschers U, Kataria T (2002) Age effects on urethral striated muscle. I. changes in number and diameter of striated muscle fibers in the ventral urethra. Am J Obstet Gynecol 186(3):351-355

33. Trowbridge ER, Wei JT, Fenner DE, Ashton-Miller JA, Delancey JO (2007) Effects of aging on lower urinary tract and pelvic floor function in nulliparous women. Obstet Gynecol 109(3):715720. doi:10.1097/01.AOG.0000257074.98122.69 